\title{
Mechanical behavior analysis of a Friction Stir Welding (FSW) for welded joint applied to polymer materials
}

\author{
Hachellaf Kaddour, Meddah Hadj Miloud, Ould chikh El Bahri, Lounis Abdellah \\ University of Mascara, LSTE Laboratory, 29000, Mascara, Algeria. \\ kaddour.bachellaf@univ-mascara.d\%, bttp:/ /orcid.org/0000-0001-2345-6789 \\ hmmeddah@yahoo.fr, bttp://orcid.org/0000-0002-2345-6790 \\ b.ouldchikb@univ-mascara.d₹,bttp:/ /orcid.org/0000-0003-2345-6791 \\ lounisabdallab@gmail.com, bttp:/ /orcid.org/0000-0004-2345-6792
}

\begin{abstract}
Welding is a technique of fusion joining the material involving a process of inter-molecular diffusion adhesion. Polymer welding is an assembly method among several known assembly techniques such as gluing. This welding process applies to thermoplastics; they have the rheological or softening characteristics during melting. This process is fast and controlled in order to obtain a solid and durable mechanical connection on the series parts. This study focuses on the weldability of high density polyethylene (HDPE) using the friction stir welding technique. A parametric choice was made to optimize the operating parameters namely the shape of the welding tool, the speed of rotation and the speed of advance of the tool. Monotonic tensile tests were used to compare the mechanical characteristics between a HDPE test specimen and a specimen taken from an FSW weldment.

It emerges from this study that the FSW welding introduces a weakening of the joints characterized by a clear decrease of the deformation at break.
\end{abstract}

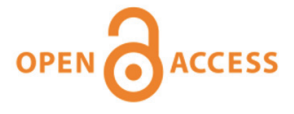

Citation: Hachellaf, K., Meddah, H. M., Ouldchikh, El. B, Lounis, A., Mechanical behavior analysis of a Friction Stir Welding (FSW) for welded joint applied to polymer materials, Frattura ed Integrità Strutturale, 47 (2018) 459-467.

Received: 02.10 .2018

Accepted: 14.12.2018

Published: 01.01.2019

Copyright: (C) 2018 This is an open access article under the terms of the CC-BY 4.0, which permits unrestricted use, distribution, and reproduction in any medium, provided the original author and source are credited.

KEYWORDS. Polymers; Tensile tests; FSW; Vickers hardness test.

\section{INTRODUCTION}

$\mathrm{F}$ riction stir welding is a recent permanent assembly process considered as a major technology in the industry, this type of welding is applied to thermoplastic materials including polymers, its principle is based on the softening phenomenon following the melting caused by the heating of the material (Fig. 1.a) assembled with a nonconsumable special rotating tool (Fig. 1.b). The principle is to provide heat to the metal base by friction of the metal by a pin fixed on a base that rotates in the joint plane of the parts to be assembled.

A metal layer in plastic and pasty form is formed under the base and around the pin. This process which performs the assembly at a temperature below the melting temperature of the metal to be bonded deforms less than the fusion processes. In addition, the mechanical characteristics of the welded materials remain close to the initial values of the base 
materials. This process is well suited to alloys with a low melting point (aluminum, magnesium, copper) and found with these materials its main industrial applications: aeronautics, space, land transport, shipbuilding etc...

During the welding operation the friction and the thermal field are factors that play an important role for the success of the FSW welding operation. The frictional heat of the shoulder of the tool and the heat of deformation of the tool spindle allow the material to soften without reaching the melting point. Significant plastic deformation and flow of this plasticized material occur as the tool is translated along the welding direction. The material is transported from the front to the rear edge of the tool, where it is forged to form a joint [1]. Panneerselvam and Lenin [1,2] observed that in the FSW of Nylon-6, a seal made with counter-clockwise rotation of the tool produced better material properties. Hoseinlaghab et al. [1,3] studied the creep properties of FSW-welded polyethylene plate assemblies and reported that under controlled conditions, the creep resistance of welds may be better than that of the base [1]. FSW can be used to join sheets and aluminum plates, without filler wire or shielding gas. Variety of materials ranging from aluminum alloys, copper, magnesium, lead, zinc and polymers and a material thickness ranging from 0.8 to $65 \mathrm{~mm}$ have been reported for successful welded joints at full penetration and without porosity and internal voids [4]. After the successful application of FSW on metals, Adeel et al. found that, depending on their physical and rheological properties, the welding parameters differ from polymer to polymer. Polymers with high melting temperature and viscosity require a higher speed of rotation and reach a sufficient heat and possibly a good resistance of the weld. In addition, to improve the welding force, the use of hot shoes or induction heating in situ showed good results [5]. Olivier L. has shown that temperature plays a key role in the success of welding and thus the understanding and control of the flow of the material are related to the temperature field and are critical for the success of FSW welding [6]. In other sense the improvement of mechanical properties such as fatigue, Zhou et al has confirmed through these tests on the service life is better in FSW (compared to other welding processes), higher service life for FSW welded joints (9 to 12 times higher) [7].

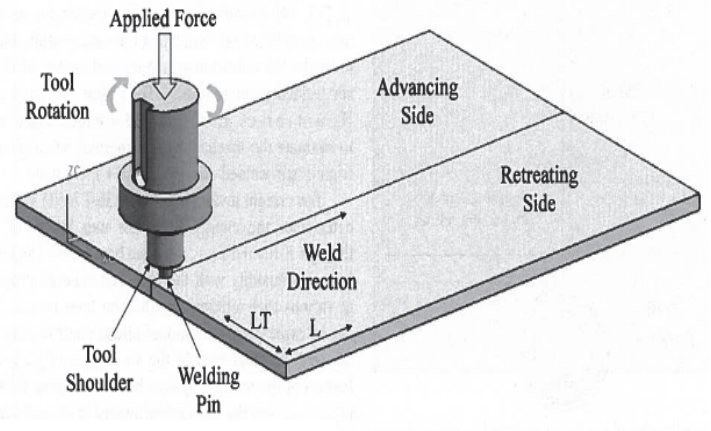

a)

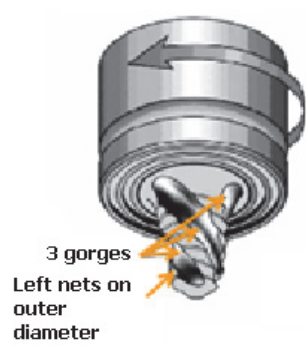

b)

Figure 1: FSW welding principle. a) FSW welding process, [8]. b) FSW welding tool, [9].

In this work we highlight the weldability of HDPE polymer by friction stir welding technique (FSW), the HDPE material is used in the drinking water networks and thus the city gas networks. Three welding parameters, the speed of rotation, the speed of advance and the geometrical shape of the tools, were studied. Mechanical behavior tests were carried out to evaluate and optimize the necessary parameters involved in achieving a good weld.

\section{EXPERIMENTAL PROCEDURE}

$\mathrm{T}$

he material used is high density polyethylene (HDPE) is a thermoplastic polymer of high diffusion. It is part of the family of polyolefins, in the same way as low or medium density polyethylenes, used in the manufacture of pipes reserved for the supply and distribution of drinking water in accordance with Algerian standards NA7700-2 manufactured by the group CHIALI Sidi Bel-Abbes (Algeria), molar mass is of the order of $500 \mathrm{~kg} / \mathrm{mol}$ and glass transition temperatures and melting are respectively $\left(-125^{\circ} \mathrm{C}\right.$ and $\left.135^{\circ} \mathrm{C}\right)$ [10]. Tabs. 1 and 2 below show the mechanical and physical properties of HDPE (PE100).

The tensile test carried out taken from a drinking water pipe made of HDPE (dumbbell type) in Fig. 2 according to the ISO 3167 standard [12]. Then perform the monotonic tensile operation to complete the main mechanical properties of a material (Fig. 3), such as yield strength, breaking strength and elongation. 


\begin{tabular}{llll}
\hline Resin's designation & $\begin{array}{l}\text { Minimal stress } \\
\text { MSR (MPa) }\end{array}$ & Required & $\begin{array}{l}\text { Long-term hydrostatic } \\
\text { Stress } \sigma(\mathrm{MPa})\end{array}$ \\
PE100 & 10 & 8 \\
PE 80 & 8 & 6.3 \\
\hline
\end{tabular}

Table 1: Resin's used for HDPE tubes [42].

\begin{tabular}{lccc}
\hline Characteristics & Units & PE80 & PE100 \\
Density & $\mathrm{kg} / \mathrm{m}^{3}$ & $949-956$ & $956-961$ \\
Melt Flow Index(MFI $\quad(190$ & & $0.7-1$ & $0.2-0.5$ \\
$\left.{ }^{\circ} \mathrm{C} ; 5 \mathrm{~kg}\right)$ & $\mathrm{g} / 10 \mathrm{mn}$ & & $\geq 19$ \\
Resistance at the yield point & $\mathrm{MPa}$ & $\geq 15$ & $>600$ \\
Elongation at break & $\%$ & $>600$ & 1000 \\
Elasticity modulus & $\mathrm{MPa}$ & 800 & $<-100$ \\
Fragility temperature & ${ }^{\circ} \mathrm{C}$ & $<-100$ & 24.104 \\
Linear expansion & $\mathrm{K}^{-1}$ & 24.104 & $\geq 1012$ \\
Electrical resistance & $\Omega / \mathrm{cm}$ & $\geq 1012$ & \\
\hline
\end{tabular}

Table 2: Physical characteristics of HDPE [10].

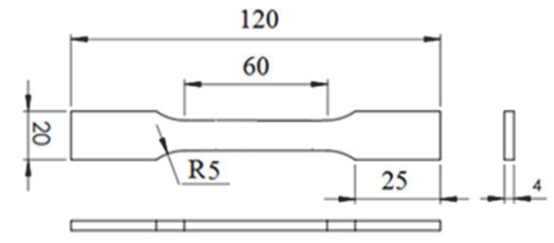

Figure 2: No welded test specimen [12].

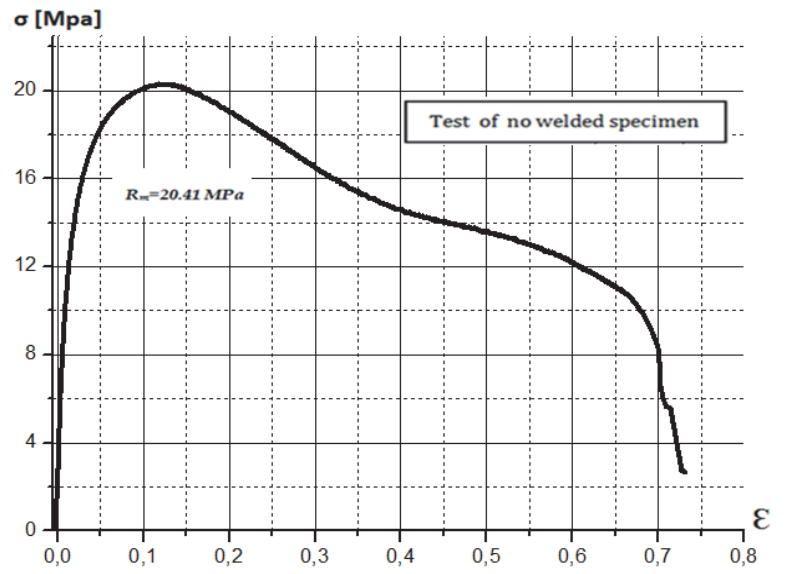

Figure 3: Stress-Strain curve (non-welded test specimen) in the strain rate.

For the investigation, samples of size $300 \mathrm{~mm}$ x $60 \mathrm{~mm}$ x $4 \mathrm{~mm}$ were used Fig. 4. Butt welding was done. The tools used are prepared by steel commonly used to ensure good mixing and good softening of the material entrained Fig. 5.

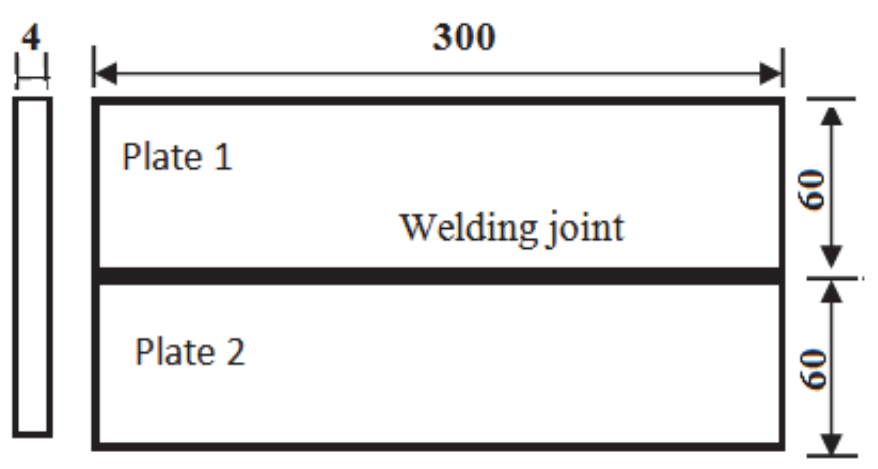

Figure 4: FSW welding sample. 


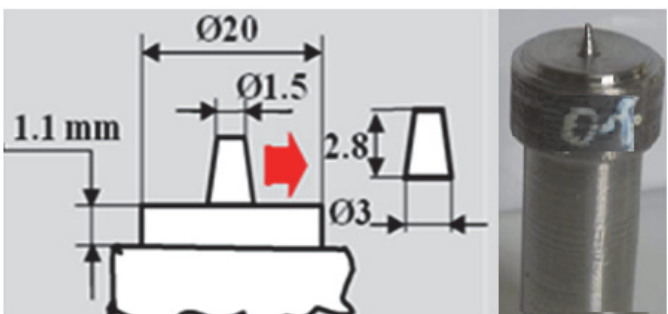

Tool T1

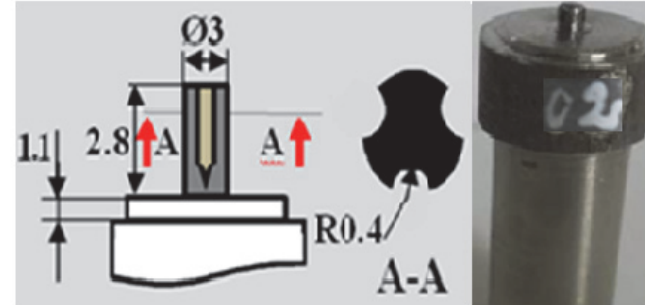

Tool T2

Figure 5: Geometry of the tools.

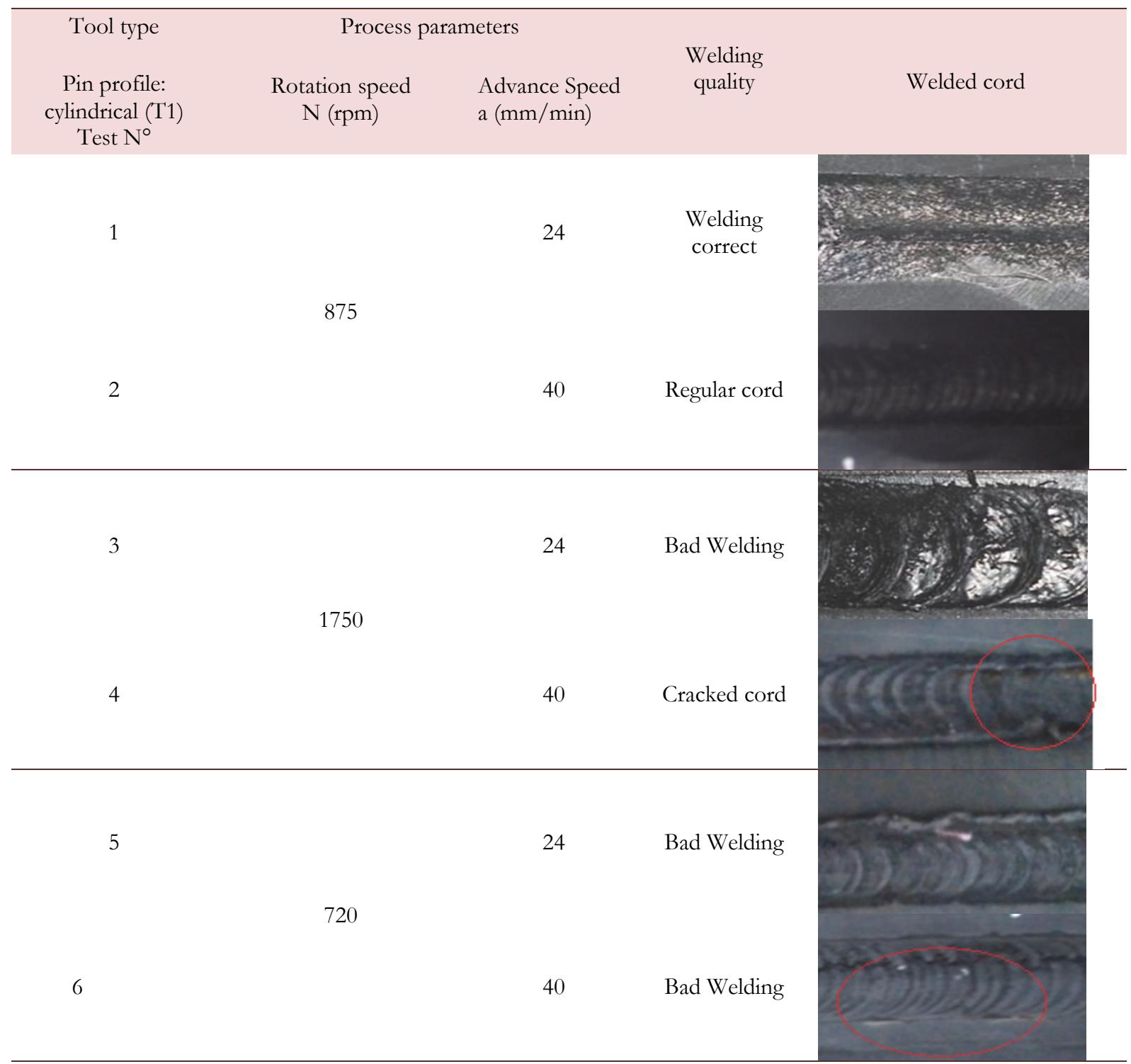

Table 3a: Welding process parameters

The material used for welding tools is ordinary steel. These tools are suitable for friction welding FSW of HDPE plates. They are able to perform the three main welding functions [13, 14]:

- Heat the parts by friction and by plastic deformation, 
- Mix the materials to form the joint

- Contain the flow of material under the shoulder and around the pin.

The shoulder serves to bring heat by friction and to confine the kneaded material under the tool.

\begin{tabular}{|c|c|c|c|c|}
\hline Tool type: & Process 1 & eters & & \\
\hline $\begin{array}{c}\text { conical (T2) } \\
\text { Test } \mathrm{N}^{\circ}\end{array}$ & $\begin{array}{l}\text { Rotation speed } \\
\quad \mathrm{N}(\mathrm{rpm})\end{array}$ & $\begin{array}{l}\text { Advance speed } \\
\text { a (mm/min) }\end{array}$ & Quality & we \\
\hline 1 & 875 & 24 & $\begin{array}{l}\text { Welding } \\
\text { correct }\end{array}$ & \\
\hline 2 & 875 & 40 & $\begin{array}{l}\text { Welding } \\
\text { correct }\end{array}$ & \\
\hline 3 & 1750 & 24 & Bad Welding & \\
\hline 4 & 1750 & 40 & Bad Welding & \\
\hline 5 & 720 & 24 & No welding & \\
\hline 6 & 720 & 40 & Cracked cord & \\
\hline
\end{tabular}

Table 3b: Welding process parameters.

\section{RESULTS AND DISCUSSIONS}

he experiment was successfully carried out on HDPE plates with a thickness of $4 \mathrm{~mm}$ with all the parameters selected.

Examination of these welded samples by both types of tools gives some good results for welding quality. The samples relating to the welding by the two tools T1 and T2 for rotation speed of $875 \mathrm{rpm}$ and advance speed of 24 and $40 \mathrm{~mm} / \mathrm{min}$ have a satisfactory appearance. For other cutting parameters, we notice a bad quality of welding. We also noticed that with a cylindrical pin, the kneading zone of the welded sample had a good surface state, which proves the effectiveness of the tool for kneading the softened polymeric material (Tab. 3).

When the linear welding operation is finished sample preparation is carried out for tensile tests (Fig. 6), tensile test specimens made of Dumbbell form according to ISO 3167. Tensile tests are carried out under room temperature. 

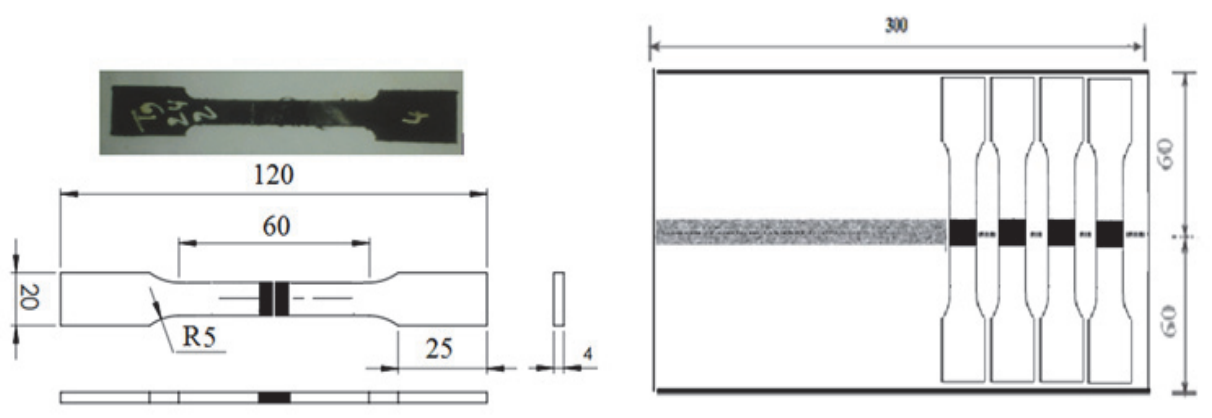

Figure 6: Welded test specimen [12].

Fig. 7 shows a typical aspect of the weld on welded plates with a rotation speed of $875 \mathrm{rpm}$ and advance speed of 24 and $40 \mathrm{~mm} / \mathrm{min}$ shown in Tab. 3 .

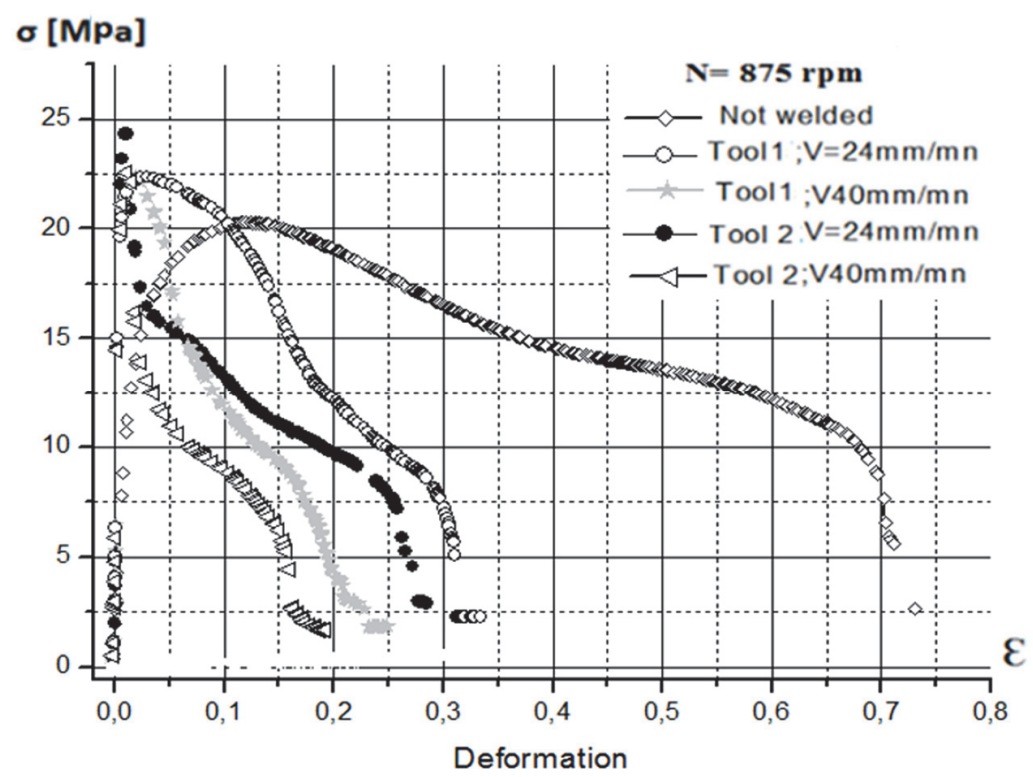

Figure 7: Law behavior of welded specimens

\begin{tabular}{|c|c|c|c|c|c|c|c|}
\hline \multicolumn{8}{|l|}{ Tool type: } \\
\hline $\begin{array}{c}\text { Conical profile } \\
\text { (T1) } \\
\text { Test } \mathrm{N}^{\circ}\end{array}$ & $\begin{array}{l}\text { Rotation } \\
\text { speed } \\
(\mathrm{rpm})\end{array}$ & $\begin{array}{l}\text { Advance } \\
\text { speed } \\
\mathrm{a}(\mathrm{mm} / \mathrm{min})\end{array}$ & $\begin{array}{l}\text { Max stress of } \\
\text { tensile test } \\
\text { Rm max } \\
(\mathrm{MPa})\end{array}$ & $\begin{array}{c}\text { Elasticity } \\
\text { module E } \\
(\mathrm{MPa})\end{array}$ & $\begin{array}{l}\text { Average } \\
\text { (x) }\end{array}$ & $\begin{array}{l}\text { Standard } \\
\text { deviation } \\
(\sigma)\end{array}$ & $\begin{array}{c}\text { Efficiency } \\
\text { rate } \\
\text { the stress of } \\
\text { the welded } \\
\text { joint } \\
(\%)\end{array}$ \\
\hline 1 & \multirow{2}{*}{875} & 24 & 22.60 & 1320 & \multirow{5}{*}{23.257} & \multirow{5}{*}{0.927} & 5.56 \\
\hline 2 & & 40 & 23.11 & 2102 & & & 7.94 \\
\hline $\begin{array}{c}\text { cylindrical } \\
\text { profile (T2) }\end{array}$ & & & & & & & \\
\hline 3 & \multirow{2}{*}{875} & 24 & 24.61 & 1500 & & & 14.94 \\
\hline 4 & & 40 & 22.71 & 1433 & & & 6.07 \\
\hline \multicolumn{3}{|c|}{ No welded sample test } & 21.41 & 920 & / & / & / \\
\hline
\end{tabular}

Table 4: Tensile strength values and their effectiveness on the welded bead. 
Tab. 4 shows the tensile strength values and their effectiveness on the weld bead for different parameters and for the two tools with cylindrical and conical pins. The cylindrical pin tool achieves maximum efficiency of the joint strength respectively $14.94 \%$ and $6.07 \%$ for advanced speed $24 \mathrm{~mm} / \mathrm{min}$ and $40 \mathrm{~mm} / \mathrm{min}$ and in parallel for the conical tool profile has a value of $13.12 \%$ for a speed of $24 \mathrm{~mm} / \mathrm{min}$.

The experimental results shown in Fig. 7 (stress-strain curves) for tensile tests with a strain rate of $0.01 \mathrm{~s}-1$ at room temperature are compared to those of the no welded test specimen. According to these results of the FSW welding on HDPE, it can be seen that these results are very satisfactory, especially the tools T1 and T2 for the two advanced speed 24 and $40 \mathrm{~mm} / \mathrm{min}$, where a remarkable improvement is observed caused by the temperature welding effect on the material that is triggered at the beginning of the tensile stress on the elastic zone (Fig. 7).

from Fig. 7, we remarked also that the maximum stress $\mathrm{Rm}=24.3 \mathrm{MPa}$ became important, an improvement of the modulus of elasticity with respect to that of the no welded specimen which was of value $\mathrm{Rm}=20.41 \mathrm{MPa}$, at the same time or we have a reduced plastic part noticing on the curves where the plasticity domain of the material (plastic side on the tensile curve) was lost, therefore the material has become rigid, the latter linked to several phenomena and several parameters influenced by the FSW welding operation and even the material as there are other parameters that play an important role, all due to the influence of the machined weld joint that changes the mechanical behavior of the FSW welded material. These experimental results obtained allowed us to better understand certain phenomena resulting for example the flow of the material around the tool.

\section{MICRO HARDNESS TEST}

he Vickers micro-hardness test is done on a very sophisticated automatic FT-ARS 9000 laboratory mechanical engineering tester with a load of $500 \mathrm{gf}$ for 10 seconds at room temperature [15].

The determination of the hardness value of the weld seams for comparing the results to those of the non-welded material, the micro-hardness was measured on the mid-thickness of the welded joints perpendicular to the welding axis are made (Fig. 8) with a step of $1 \mathrm{~mm}$ between the points measured, where the measurements are carried out symmetrically with respect to the main axis of welding.

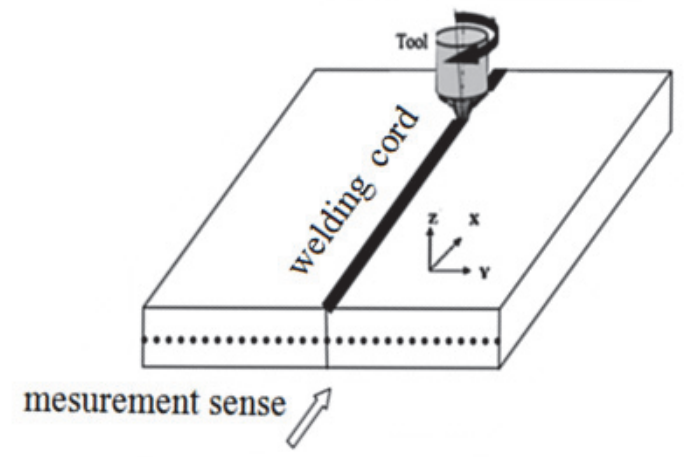

Figure 8: Profile of welded joint on half thickness.

The results of the Vickers micro-hardness (HV) shown in (Fig. 9), made on the average thickness of two welded plates (lateral side) of the welded bead (Fig. 8 ) with a spacing of $1 \mathrm{~mm}$, Within a limited range of $(-15$ to $+15 \mathrm{~mm})$ from the center of the weld, variable hardness applies over 4 main thermal zones, the core zone (or nugget zone NZ), thermomechanical affected zone (TMAZ), heat affected zone ( HAZ) and base material (BM) which is not affected by the FSW welding process. The mechanical properties vary between deferent component zones of the welding.

The micro-hardness profile exhibits an increase in all cases which reaches a maximum value at the core zone (NZ) which is the equi-axed zone is harder than the other zones, the curve is fairly symmetrically to the axis, ie the core zone is very hard relative to the base material zone BM. the micro-hardness decreases towards the less hard zone, the latter represents the normal state of the non-welded material, this zone is located outside the thermal deformation during welding, so it retains its original granular structure without change. According to [16, 17] the hardness value in the NZ zone should be higher than the other zones because of its structure. The distribution of microhardness is almost symmetrical with respect to the median weld line because the field plastic flow on both sides of the weld center is uniform [16, 18]. 


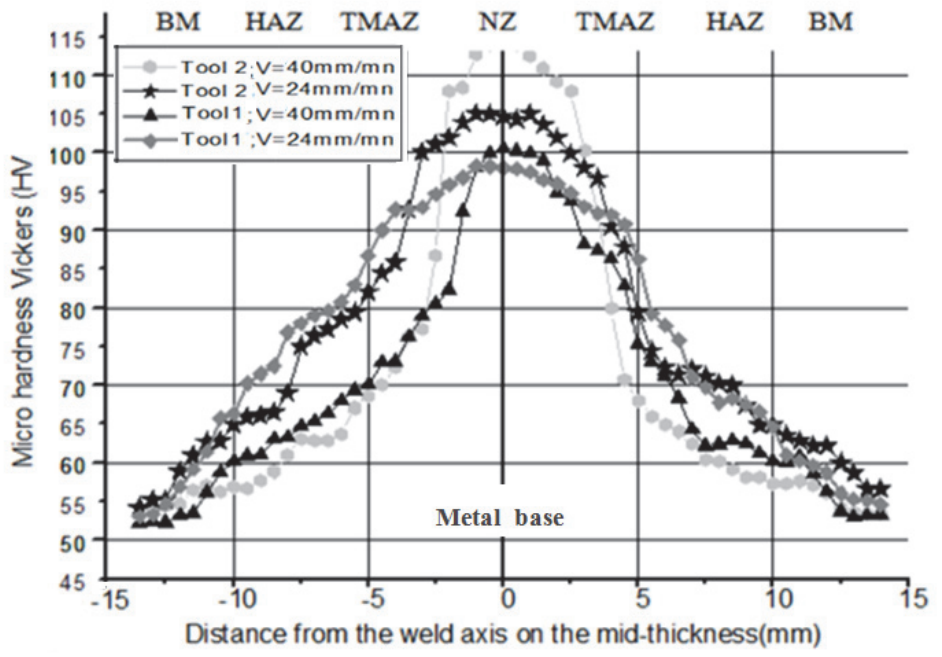

Fig. 9.: Variation of micro-hardness Vickers HV.

\section{CONCLUSIONS}

he characterization of the mechanical behavior of the materials through the various tests carried out, the results obtained show the complex relationship between material and tool which contributes to the physicochemical change modified by several welding parameters such as the advance speed, the rotation speed and tool geometry. This study, we concluded that the behavior of the welded joint FSW strongly depends on the geometry of the tool which plays an important role with the chosen parameters. The union of all these parameters proves that FSW welding of HDPE gives very satisfactory and important results. It should be noted that the analysis of the results made it possible to understand the influence of the tool geometry and cutting parameters used in FSW.

According to the results obtained, it is observed that the best results were obtained by the cylindrical profiled tool T2 which have a maximum efficiency of the weld of 14.94\% compared to the base material, better than the tool T1 with a conical profile which reaches a efficiency of $7.94 \%$, the cylindrical profile with a dynamic volume ratio produces better results than the conical profile are suitable to obtain a good quality of welding of thermoplastic materials such as HDPE. This work is a real experimental challenge. To do this, we have developed a technique for welding HDPE. With regard to the influence of tool geometry on FSW welding, tools T1 and T2 are suitable for obtaining good welding quality.

\section{REFERENCE}

[1] Vijendra, B., Sharma, A. (2015). Induction heated tool assisted friction-stir welding (i-FSW): A novel hybrid process for joining of thermoplastics, J. Man. Proces. 20, pp. 234-244. DOI:10.1016/j.jmapro.2015.07.005.

[2] Panneerselvam, K., Lenin, K. (2014). Joining of Nylon 6 plate by friction stir welding process using threaded pin profile, J. Mater. Design, 53, pp. 302-307. DOI: 10.1016/j.matdes.2013.07.017.

[3] Hoseinlaghab, S., Mirjavadi, S.S., Sadeghian, N., Jalili, I., Azarbarmas, M., Givi, (2015). Influences of welding parameters on the quality and creep properties of friction stir welded polyethylene plates, J. Mater Design, 67, pp. 369-378.

[4] Patel, A. R., Dalwadi, C.G. (2016). A Review: Dissimilar Material Joining of Metal to Polymer using Friction Stir Welding (FSW). Inter J. Sci. Technology \& Engineering, 2(10), pp. 702-706.

[5] Zafar, M., Awang, M., Raza Khan, S. (2017). Friction Stir Welding of Polymers. 2nd International Conference on Mechanical, Manufacturing and Process Plant Engineering, Lecture Notes in Mechanical Engineering, pp. 19-36.

DOI 10.1007/978-981-10-4232-4_2.

[6] Lorrain O., ed., (2010). Analyses expérimentale et numérique du procédé de soudage par friction malaxage FSW, Paris Tech, Thèse de doctorat, l'Ecole Nationale Supérieure d'Arts et Métiers, Paris Tech.

[7] Zhou, C., Yan, X., Luan, G. (2005). Fatigue properties on friction stir welding in Al 5083, J. Scripta Materialia, 53(10), pp.1187-1191. DOI 10.1016/j.scriptamat.2005.07.028. 
[8] Hamilton, C., Dymek, S., Bucharski, M., (2008). Friction stir welding of Aluminum 7136-T 76s11 Extrusions. J. Sci. And Technology of Welding And Joining, 13(8), pp. 714-720.

[9] Mishra, R.S., Ma, Z.Y. (2005). Friction stir welding and processing, J. Mat. Sci. and Engineering, 50, pp. 1-78.

[10] Catalogue technique pour tubes en polyéthylènePE, Groupe CHIALI de Sidi Bel-Abbes- Algeria, Available at (2017): http:/www.groupe-chiali.com.

[11] Catalogue société CONCEPTCUVE société de chaudronnerie plastique de france ; contact@conceptcuve.com; France, Available at (2017): https:/ /www.conceptcuve.com/polyethylene-pehd.htm.

[12] ASTM D 638 Standard Test Method for Tensile Properties of Plastics. (2017).

[13] Thomas, W.M., (1991). Friction stir welding, J. Inter. Patent Appl. no.PCT/GB92/02203 and GB Patent Application no. 9125978.8, US. Patent no. 5,460, 317.

[14] Shigeki, H., Harsha, B., Kazutaka, O., Toshio, T., Tsuyoshi, K., (2010). Analysis of effect of tool geometry on plastic flow during friction stir spot welding using particle method, J.of Mat. Proc. Tech., 210, pp. 1455-1463.

[15] Hardness Tester Fully-Automatic Micro/Vickers Hardness. Fv-Ars 9000, Avaible at (2017): www.ft-hardness.com

[16] Chen, Z., Shengxi, Li. Lloyd, H. (2015). Microstructure, mechanical properties and corrosion of friction stir welded 6061 Aluminum Alloy, Hawaii Corrosion Laboratory, Department of Mechanical Engineering, University of Hawaii at Manoa, Honolulu, HI 96822, USA, pp.1-25.

[17]Jeong, D. H., Erb, U., Aust, K. T., Palumbo G., (2003). The relationship between hardness and abrasive wear resistance of electrodeposited nanocrystalline Ni-P coatings, J. Scripta Materialia, 48 (2003), pp. 1067-1072

[18] Xu, W., Liu, J., Luan, G., Dong, C. (2009). Microstructure and mechanical properties of friction stir welded joints in 2219-T6 aluminum alloy, J. Materials \& Design, 30, pp. 3460-3467. 